\title{
Influence of Acoustic Black Hole Array Embedded in a Plate on Its Energy Propagation and Sound Radiation
}

\author{
Haoming Liang ${ }^{1}$, Xiandong Liu ${ }^{2, *}$, Jiakai Yuan ${ }^{3}$, Yue Bao ${ }^{4}$, Yingchun Shan ${ }^{5}$ and Tian He 6 \\ Beihang University; liang0605@buaa.edu.cn \\ 2 Beihang University; liuxiandong@buaa.edu.cn \\ 3 Beihang University; yuanjiakai@buaa.edu.cn \\ 4 Beihang University; baoyue@buaa.edu.cn \\ 5 Beihang University; shanych@buaa.edu.cn \\ 6 Beihang University; hetian@buaa.edu.cn \\ * Correspondence: liuxiandong@buaa.edu.cn.
}

\begin{abstract}
The plate embedded with acoustic black hole $(\mathrm{ABH})$ indentations is potential for structural vibration and noise control. This work focuses on the mid- and low-frequency performance of plates embedded with the array of $\mathrm{ABH}$ for energy focalization and vibration \& noise suppression. Plates embedded with two-dimensional ABHs are modelled with detailed Finite Element (FE) models, and the power flow method is introduced to analyze the energy propagation characteristics arising from $\mathrm{ABH}$ effect. Then the distribution of average vibration power density along $\mathrm{ABH}$ radius is studied. Next, the energy dissipation effects of the plate model embedded with ABH array with two types of damping layers are investigated. Finally, the sound pressure levels of the ABH structure are calculated and discussed. This work is helpful to understand the characteristics of plates embedded with $\mathrm{ABH}$ array in reducing vibration and noise radiation. Results show the tremendous potential of $\mathrm{ABH}$ array for vibration and noise control.
\end{abstract}

Keywords: Acoustic black hole; vibration control; energy propagation

\section{Introduction}

To control the car interior noise, a great deal of damping material is pasted in the car body plate. This increases the car weight and produces a contradiction with the lightweight design intention. To increase the energy dissipation efficiency of the damping material will certainly reduce the usage of damping material for the identical noise reduction effect. The main feature of $\mathrm{ABH}$ in the plate structure is that it can guide the flexural wave to the central area of $\mathrm{ABH}$ and make this area have high vibration amplitude. So pasting damping material on this area is expected to lead to high energy dissipation efficiency. On the other hand, the gradually reducing thickness of $\mathrm{ABH}$ structure may reduce the weight of plate embedded with ABHs. Apparently, the body panel embedded with twodimensional $\mathrm{ABH}$ indentations is potential to solve this contradiction.

The concept of ABH effect was initially presented by Mironov [1] in investigating the propagation of a flexural wave in a plate with a power-law profile. However, the main problem in utilizing this effect is that an ideal one-dimensional $\mathrm{ABH}$ structure is difficult to be realized because of the existing machining capability, that is, a truncation must be included to the edge of the plate. As a result, the reflection of the flexural wave in the plate greatly increases and the ABH effect remarkably weakens. Krylov et al. [2-3] suggested that the presence of a small amount of damping layers on $\mathrm{ABH}$ can reduce the reflection coefficients significantly, despite the truncations. This effect had been demonstrated by using experimental investigation [4] and it also showed appealing potential in sound radiation control [5-6]. 
A two-dimensional $\mathrm{ABH}$ is materialized by a cylindrically symmetrical indentation of power-law profile whose exponent is equal or larger than two. An important advantage of two-dimensional $\mathrm{ABH}$ is that it can be embedded in a plate structure, which can widen the range of application. Many works on single two-dimensional ABH have been done by using the analytical method. Yan et al. [7] and Krylov [8] applied the geometrical acoustic theory to calculate the beam trajectories in the region of two-dimensional ABH structure, and the results showed that rays of waves propagated through the two-dimensional $\mathrm{ABH}$ region deflect to its central area. O'Boy and Krylov et al. [9-10] used the exact solution of the corresponding flexural wave equation to analyze the frequency response for circular and rectangular plates with and without $\mathrm{ABH}$. They found that despite the imperfect thickness profile, two-dimensional $\mathrm{ABH}$ structures with appropriate damping layers can also absorb a substantial amount of the wave energy [8-10]. Huang et al. [11] proposed a numerical integration scheme of the flexural ray equation to predict the ray trajectories of waves and investigated the wave focalization properties in two-dimensional ABH indentations. The plate embedded with a single two-dimensional $\mathrm{ABH}$ can address vibration absorption characteristics at higher frequencies where the plate bending wavelengths are smaller than the $\mathrm{ABH}$ characteristic dimension. However, for the vehicle body structure demanding better vibration and noise control performance at lower frequencies, the size of an $\mathrm{ABH}$ is limited since the size and shape of plates in body structure. These limit the applicability of embedded ABHs as vibration and noise control solutions. Fortunately, the $\mathrm{ABH}$ array is potential to improve the low-frequency vibration control performance of the plate structure [5]. To understand the mechanisms of the flexural wave propagating in $\mathrm{ABH}$ area, the analytical method can be used. However, this method is difficultly used to investigate the complex structures such as the plates embedded with multiple two-dimensional ABHs.

Numerical simulation based on finite element method (FEM) can overcome the shortcoming of the analytical method and be applied to both frequency domain analysis and time-domain analysis of $\mathrm{ABH}$ structures. Conlon et al. [13] used the finite element and boundary element models to investigate the vibration and noise performance of plates embedded with periodic grids of embedded two-dimensional ABHs, and pointed out that the periodic $\mathrm{ABH}$ array may improve the low-frequency vibration control performance of the structure. Methods for enhancing low-frequency performance of ABH effect were illustrated and the role that local ABH cell modes/modal density play in vibration suppression was also investigated by Conlon et al. [5,13]. Huang et al. [14] investigated the influence of structural parameters on energy focalization positions of the bending wave by using FEM. Prill et al. [18] established a FE model of a car main floor embedded with 10 $\mathrm{ABHs}$, and its vibration response under a wind load excitation was studied. Results of simulation showed that noise reduction was found in the whole frequency range above $200 \mathrm{~Hz}$. These studies have achieved certain results, and most researchers use radiated sound power or vibration acceleration to express the energy focalization characteristics of $\mathrm{ABH}$ structures. However, the visualization research on vibration energy propagation process in the $\mathrm{ABH}$ area is limited still. And the characteristics of energy propagation in a plate embedded with two-dimensional $\mathrm{ABH}$ array have not been investigated systematically. In general, the systematic theory and method of two-dimensional ABH array design have not yet been formed. And the research on low-frequency vibration reduction performance of $\mathrm{ABH}$ array is not enough. Therefore, at current stage, it is difficult to guide the design of body panels that can achieve both vibration \& noise suppression and lightweight.

Aiming at these problems, in this paper, a thin-plate embedded with an array of five $\mathrm{ABH}$ cells is designed, and its energy propagation and sound radiation performance due to concentrated load is examined using FEM. The structural intensity is computed in order to quantitatively evaluate the plate structure's energy focalization performance. The overall goal of this work was to develop detailed results for the energy propagation and focalization effects of the $\mathrm{ABH}$ plate, to investigate the energy distribution of the high energy 
density area of the individual $\mathrm{ABH}$ cell of the array, to study the influence of damping materials and plate boundary conditions on energy propagation, and to explore the sound radiation performance of the plate embedded with $\mathrm{ABH}$ array. This work can provide a method for car body panel design and has the potential for solving the contradiction between vibration suppression and automobile lightweight.

\section{Modeling and Simulation Analysis of Plate Embedded with Two-dimensional ABH Array}

\subsection{Finite Element Model of Plate Embedded with ABH Array}

The profile of a two-dimensional ABH indentation is schematically shown in Fig. 1. In this paper, the two-dimensional ABHs are embedded in a uniform plate with thickness of $h_{2}$. Thickness of the central plateau (residual thickness) is $h_{1}$, and its radius is $x_{1}$ and the power index $m$ is set as 2.2. Then the thickness profile of $\mathrm{ABH}$ can be described as:

$$
h(x)=\left\{\begin{array}{c}
h_{1}, x \leq x_{1} \\
\varepsilon x^{2.2}, x_{1} \leq x \leq x_{2}
\end{array}\right.
$$
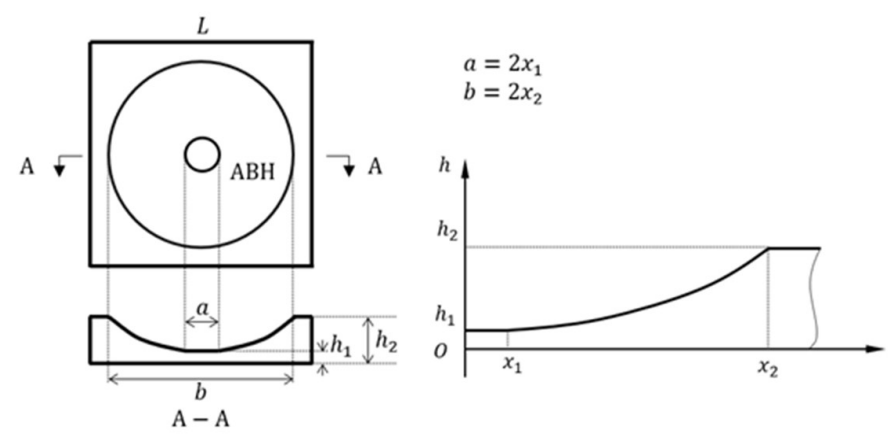

Figure 1. A typical two-dimensional $\mathrm{ABH}$ indentation.

Geometric parameters of a single two-dimensional ABH indentation in the simulation are described in Table 1.

Table 1. Geometrical parameters of the two-dimensional ABH in the simulation.

\begin{tabular}{cccc}
\hline Parameter & $h_{1}[\mathrm{~m}]$ & $h_{2}[\mathrm{~m}]$ & $x_{2}[\mathrm{~m}]$ \\
\hline Small ABH & 0.0001 & 0.004 & 0.06 \\
Big ABH & 0.0001 & 0.004 & 0.1342 \\
\hline
\end{tabular}

The commercial finite element code Abaqus is adopted for the computation of vibration response in the plate models subject to a harmonic point force with a value of $1 \mathrm{~N}$ and normal to the surface as shown in Fig. 2. In this paper, a plate with thickness of $0.004 \mathrm{~m}$ is chosen for verifying the characteristics and advantages of the plate embedded with $\mathrm{ABH}$ array in the energy propagation and sound radiation. And the geometry dimension of the plate is $0.5 \mathrm{~m} \times 0.5 \mathrm{~m} \times 0.004 \mathrm{~m}$ (length $\times$ width $\times$ thickness).
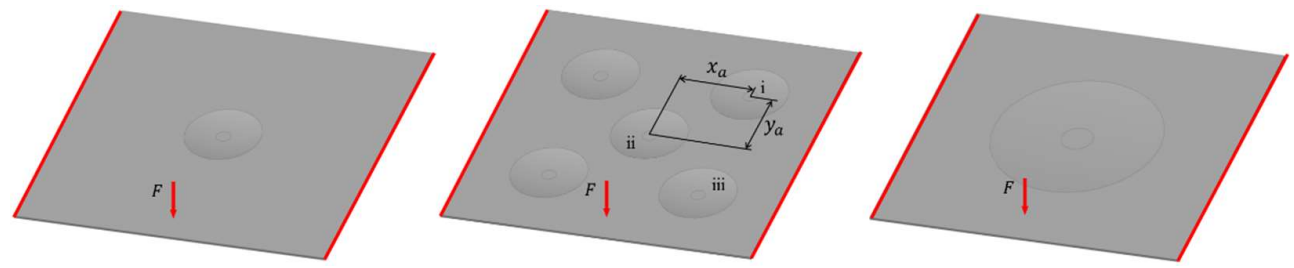
(a)

(b) (c)

Figure 2. FE models of the plate embedded with two-dimensional $\mathrm{ABH}$ : (a) Single $\mathrm{ABH}$, (b) $\mathrm{ABH}$ array, (c) Big ABH.

The so-called cut-on frequency [5] is an indicative frequency at which the wavelength of the incident bending waves starts to be equal to the characteristic dimension (the diameter in this case) of the $\mathrm{ABH}$ pit. It can be defined as:

$$
f_{\text {cut }-o n}=\frac{\pi h}{2\left(R_{A B H}\right)^{2}} \sqrt{\frac{E_{\mathrm{p}}}{12 \rho_{p}\left(1-v_{p}^{2}\right)}}
$$

where $h$ represents the thickness of the uniform part of the plate; $R_{A B H}$ denotes the radius of the $\mathrm{ABH}$ indentation; $E_{\mathrm{p}}$ is the Young's modulus of the plate material; $\rho_{p}$ represents mass density and $v_{p}$ is the Poisson's ratio.

Eq. (2) shows that the $\mathrm{ABH}$ indentation with a larger radius will have lower cut-on frequency and may have better energy focalization performance at lower frequency. To investigate the potential advantages of $\mathrm{ABH}$ array at lower frequency, 3 plate models are established and shown in Fig. 2, such as the plates respectively with a single $\mathrm{ABH}$ and the array of five same ABHs and a big ABH. Parameters $h_{1}$ and $h_{2}$ of the big $\mathrm{ABH}$ (Fig. 2(c)) are the same as those of the small $\mathrm{ABH}$ (Fig. 2(a)). And Radius $x_{2}$ of the big ABH is 134.2 $\mathrm{mm}$ to ensure that the plate with a big $\mathrm{ABH}$ has the same volume as the plate embedded with $\mathrm{ABH}$ array. The geometric parameters of the small $\mathrm{ABH}$ and the big $\mathrm{ABH}$ in this simulation are described in Table 1 . The left and right edges of the plate model are fixed and the material properties of the plate used in this paper are shown in Table 2.

Table 2. Material properties of the plate used in the simulation.

\begin{tabular}{cccc}
\hline Parameter & $\rho_{p}\left[\mathrm{~kg} / \mathrm{m}^{3}\right]$ & $E_{\mathrm{p}}[\mathrm{GPa}]$ & $v_{p}$ \\
\hline Value & 2710 & 75 & 0.3135 \\
\hline
\end{tabular}

As the $\mathrm{ABH}$ array structure is symmetrical, this paper focused on three typical $\mathrm{ABH}$ in Fig. 2(b), named $\mathrm{ABH}(\mathrm{i}), \mathrm{ABH}(\mathrm{ii})$ and $\mathrm{ABH}(\mathrm{iii})$, respectively. The center of $\mathrm{ABH}(\mathrm{ii})$ is located on the center of the whole plate structure, and the coordinates of $\mathrm{ABH}(\mathrm{i})$ is $\left(x_{a}, y_{a}\right)=(0.12 \mathrm{~m}, 0.12 \mathrm{~m})$ relative to $\mathrm{ABH}(\mathrm{ii})$, while the relative coordinates of $\mathrm{ABH}(\mathrm{iii})$ is $(0.12 \mathrm{~m},-0.12 \mathrm{~m})$. The harmonic point force is applied at $(0.12 \mathrm{~m},-0.21 \mathrm{~m})$ relative to $\mathrm{ABH}(\mathrm{ii})$.

\subsection{Energy Focalization Analysis of Different ABH Configurations}

The power flow method is very useful for the investigation of energy propagation in a structure [15-16], and can be used to describe the energy distribution and propagation. The energy focalization in the ABH areas can be analyzed by using structural power flow method [14].

Structure power flow represents the energy dissipation ability of the structure per unit time. The instantaneous power flow is defined as the product of the force and the velocity in the same direction and phase. And for FE simulation, the stress state at any point in the elastic body can be represented by six stress components, namely normal stress $\sigma_{x}, \sigma_{y}, \sigma_{z}$, and shear stress $\tau_{x y}, \tau_{y z}, \tau_{z x}$. Structural intensity defined as power flow per unit area can be expressed as [17]: 


$$
I_{n}=-\frac{1}{2} \operatorname{Re}\left(\sigma_{n} v_{n}^{*}+\tau_{n 1} v_{1}^{*}+\tau_{n 2} v_{2}^{*}\right)
$$

where $\sigma_{n}$ represents normal stress in the normal direction; $\tau_{n 1}$ and $\tau_{n 2}$ are shear stress in the direction of 1 and $2, v_{n}^{*}, v_{1}^{*}$ and $v_{2}^{*}$ indicate complex conjugate of velocities in the normal n, 1 and 2 direction, respectively.

By FE simulation of the plate embedded with ABHs (Fig. 2) excited by a harmonic force, the nodal velocity vector $\{v\}=\left\{v_{x}, v_{y}, v_{z}\right\}$ and the nodal displacement vector $\{u\}=\left\{u_{x}, u_{y}, u_{z}\right\}$ (where $\{u\}$ is $\{v\} / i \omega$ ) can be calculated. Then for a single solid element, the structural intensity of direction $\mathrm{x}, \mathrm{y}$ and $\mathrm{z}$ can be expressed as:

$$
\begin{aligned}
& I_{x}=-\frac{\omega}{2} \operatorname{Im}\left(\sigma_{x} u_{x}^{*}+\tau_{x y} u_{y}^{*}+\tau_{x z} u_{z}^{*}\right) \\
& I_{y}=-\frac{\omega}{2} \operatorname{Im}\left(\sigma_{y} u_{y}{ }^{*}+\tau_{y x} u_{x}^{*}+\tau_{y z} u_{z}^{*}\right) \\
& I_{z}=-\frac{\omega}{2} \operatorname{Im}\left(\sigma_{z} u_{z}^{*}+\tau_{z x} u_{x}^{*}+\tau_{z y} u_{y}^{*}\right) \\
& p_{d i}=\sqrt{I_{x}^{2}+I_{y}^{2}+I_{z}^{2}}
\end{aligned}
$$

where $I_{x}, I_{y}$ and $I_{\mathrm{z}}$ indicate the structural intensity in the $\mathrm{x}, \mathrm{y}$ and $\mathrm{z}$ direction, respectively; $p_{d i}$ is the modulus of structural intensity at a certain node; $\omega$ is the circular frequency, $u_{x}{ }^{*}, u_{y}{ }^{*}$ and $u_{z}{ }^{*}$ indicate complex conjugate of displacement in the normal $\mathrm{x}, \mathrm{y}$ and $z$ direction, respectively.

Real and imaginary parts of values of stress components $\sigma_{x}, \sigma_{y}, \sigma_{z}, \tau_{x y}, \tau_{y z}, \tau_{z x}$ and values of displacement components $u_{x}{ }^{*}, u_{y}{ }^{*}, u_{z}{ }^{*}$ in the frequency domain can be obtained from FE computing results. Then the structural intensity of each node in the ABH central plateau can be calculated. Higher vibration energy means higher dissipation efficiency when damping layers are coated. Therefore, the energy focalization ability can describe the performance of the plate with different ABH configurations in Fig. 2 . The vibration energy gathered in ABH central plateau as defined in Eq. (5) is calculated in the frequency band of $5-5000 \mathrm{~Hz}$, the results are shown in Fig. 3.

$$
W_{p f}=S_{c} \cdot \frac{\sum p_{d i}}{N_{c}}
$$

where $W_{p f}$ represents the vibration energy (average power flow) in a certain area per unit time; $p_{d i}$ represents structural intensity at the ith node; $N_{c}$ is the number of total nodes at the selected section and $S_{c}$ is the area of the central plateau. 


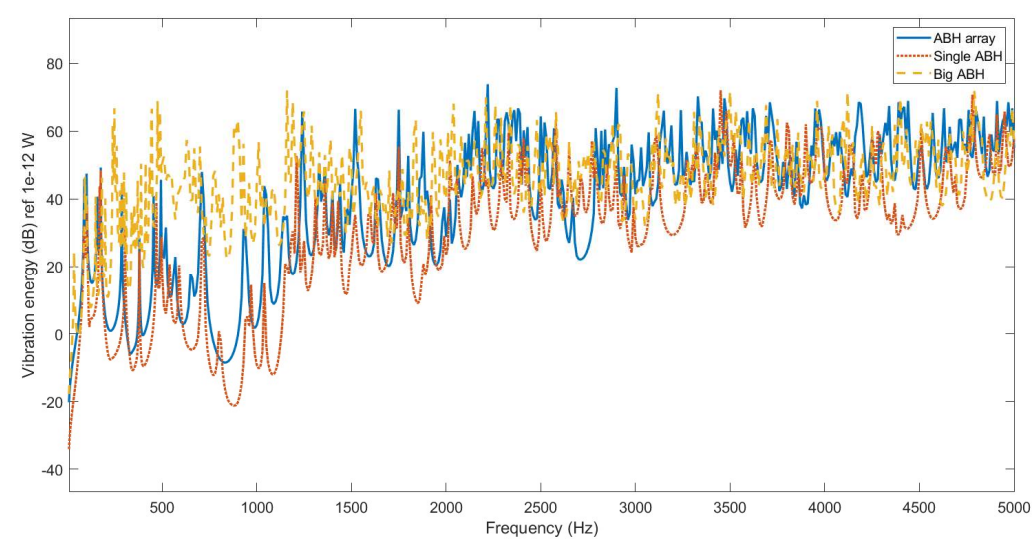

(a)

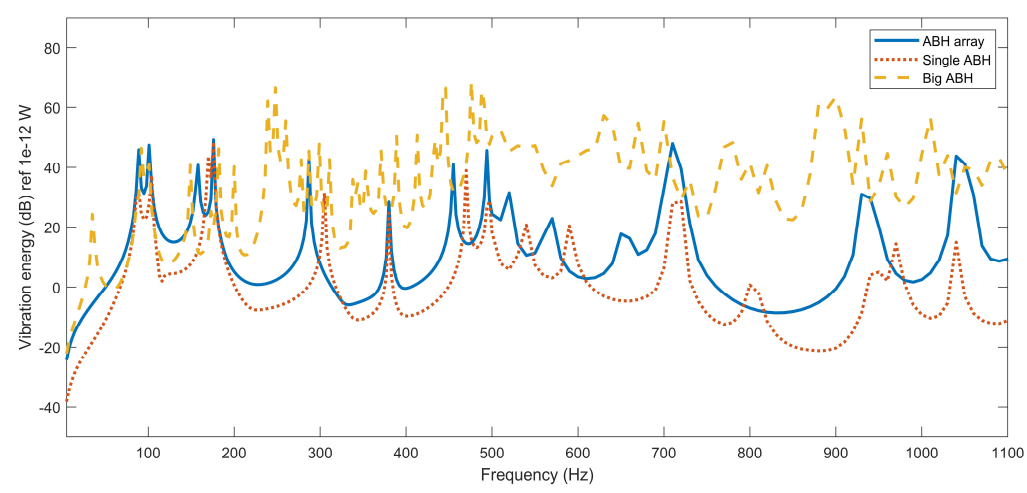

(b)

Figure 3. Vibration energy comparison among three ABH plate configurations. (a) 5-5000 Hz, (b) 5$1050 \mathrm{~Hz}$.

The cut-on frequency of the big $\mathrm{ABH}$ is $559.5 \mathrm{~Hz}$ and that of the small $\mathrm{ABH}$ is 2790.5 $\mathrm{Hz}$ according to Eq. (2). Fig. 3(a) shows that in the frequency band of $200-2200 \mathrm{~Hz}$, the overall level of vibration energy of the central plateau of the big $\mathrm{ABH}$ is the highest, followed by the plate embedded with $\mathrm{ABH}$ array and the plate with a small $\mathrm{ABH}$. Above the cut-on frequency of the small $\mathrm{ABH}(2790.5 \mathrm{~Hz})$, the energy focalization performance of the $\mathrm{ABH}$ array is gradually better than that of the big $\mathrm{ABH}$, which shows the potential for vibration and noise control at high frequencies. However, it can be seen from Fig. 3(b) that in the lower frequency band of $50-180 \mathrm{~Hz}$, the first resonant peak of the $\mathrm{ABH}$ array is slightly higher than that of the big $\mathrm{ABH}$ and is about $16 \mathrm{~dB}$ higher than that of the small single $\mathrm{ABH}$. In the same frequency band, the other resonant peaks of $\mathrm{ABH}$ array can be higher than those of the big $\mathrm{ABH}$ and single $\mathrm{ABH}$ by 1-7 $\mathrm{dB}$. The better energy gathering performance may be attributed to the low-order modes of the plate embedded with $\mathrm{ABH}$ array. For the low-frequency excitation cases, compared with the $\mathrm{ABH}$ with a large radius, the arrangement of the plate embedded with $\mathrm{ABH}$ array is more flexible, which is conducive to its application in compact structures such as vehicle body panels.

\subsection{Analysis of Energy Propagation in Plate Embedded with ABH Array}

According to the simulation data of the nodes within each $\mathrm{ABH}$ area $(\mathrm{ABH}(\mathrm{i}), \mathrm{ABH}(\mathrm{ii})$ and $\mathrm{ABH}(\mathrm{iii})$ ) and Eq. (4), the structural intensity $I_{x}, I_{y}$ and $I_{z}$ can be calculated. To reflect the power flow propagation characteristics in the $x-y$ plane, a series of power flow transmission graphs can be obtained by using $I_{x}$ and $I_{y}$ in MATLAB. In this section, 
two boundary conditions (BC 1: right and left edges of the plate are fixed, BC 2: all edges are fixed) are considered, as shown in Fig. 4. For the plate embedded with ABH array as shown in Fig. 2(b), under two different boundary conditions and at different excitation frequencies $(1000 \mathrm{~Hz}, 1050 \mathrm{~Hz}$, and $1100 \mathrm{~Hz}$ ), power flow transmission graphs of $\mathrm{ABH}(\mathrm{i})$, (ii) and (iii) in $x-y$ plane are shown in Fig. 5, Fig. 6 and Fig. 7, respectively. The length of arrows in these graphs represents the relative magnitude of power flow density (power flow per unit area) vector, while the orientation of arrows indicates the direction of power flow.

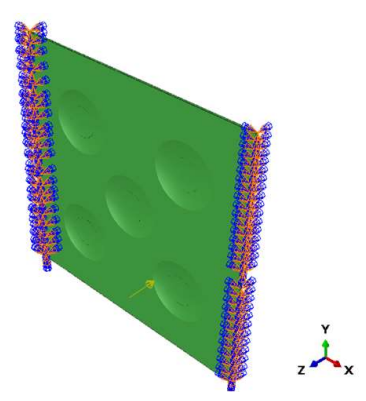

(a)

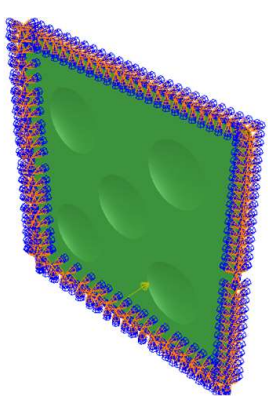

(b)

Figure 4. Two boundary conditions in this work: (a) BC1: left and right edges of the plate are fixed, (b) BC 2: all edges of the plate are fixed.

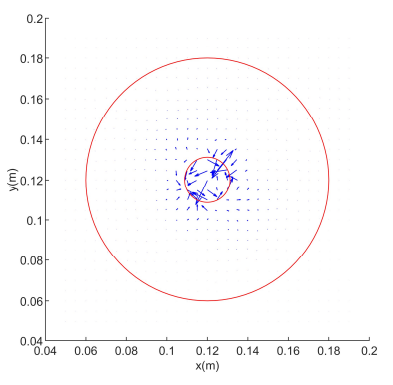

(a)

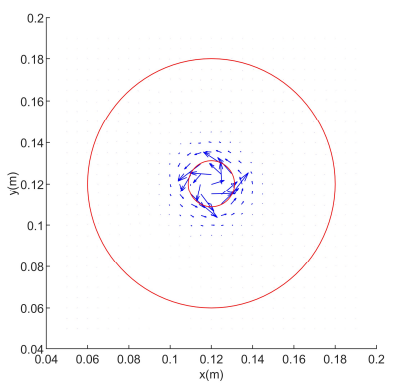

(d)

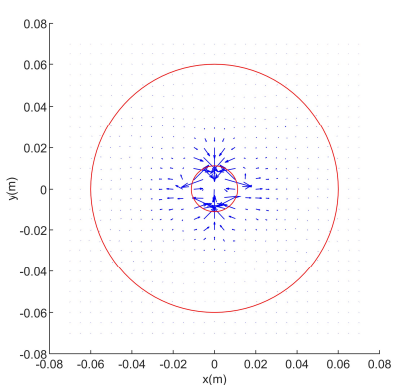

(b)

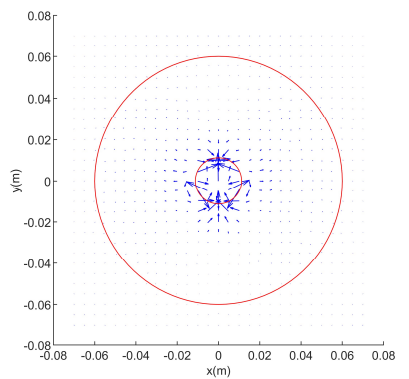

(e)

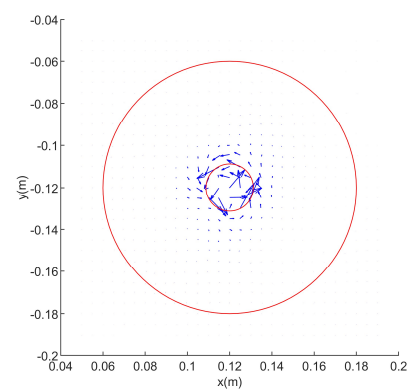

(c)

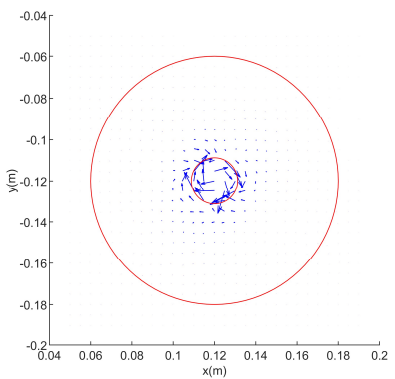

(f)

Figure 5: Power flow transmission graphs at an excitation frequency of $1000 \mathrm{~Hz}$ in $x-y$ plane: (a) $\mathrm{ABH}(\mathrm{i})$ with $\mathrm{BC} 1$, (b) $\mathrm{ABH}(\mathrm{ii})$ with $\mathrm{BC}$ 1, (c) $\mathrm{ABH}$ (iii) with $\mathrm{BC} 1$, (d) $\mathrm{ABH}$ (i) with $\mathrm{BC}$ 2, (e) $\mathrm{ABH}$ (ii) with $\mathrm{BC} 2$, (f) $\mathrm{ABH}(\mathrm{iii})$ with $\mathrm{BC}$. 


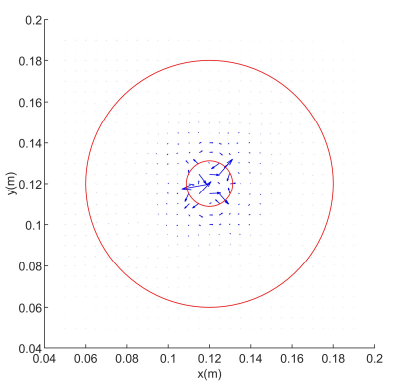

(a)

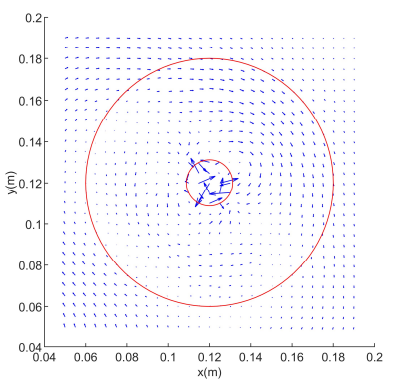

(d)

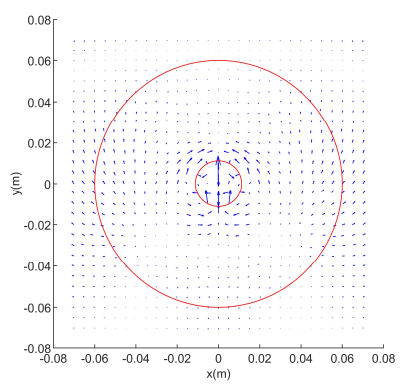

(b)

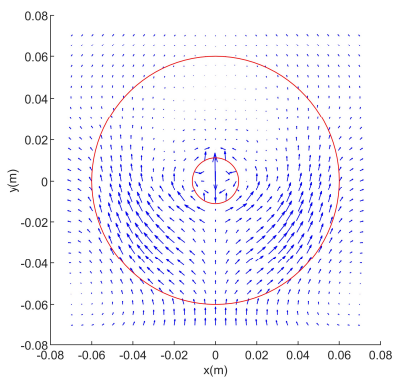

(e)

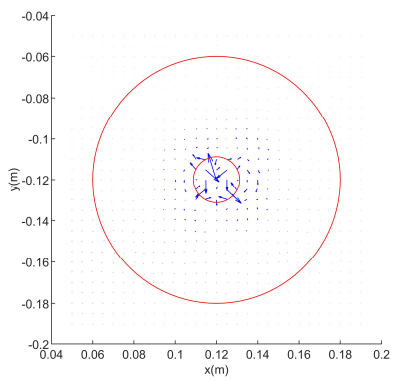

(c)

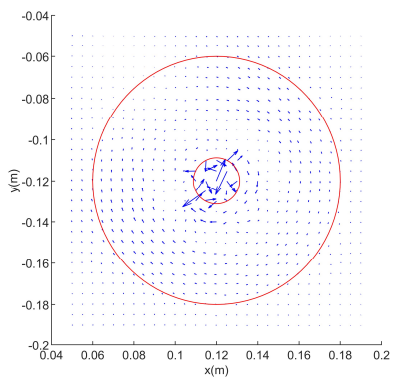

(f)

Figure 6. Power flow transmission graphs at an excitation frequency of $1050 \mathrm{~Hz}$ in $\mathrm{x}-\mathrm{y}$ plane: (a) $\mathrm{ABH}(\mathrm{i})$ with $\mathrm{BC} 1$, (b) $\mathrm{ABH}(\mathrm{ii})$ with $\mathrm{BC} 1$, (c) $\mathrm{ABH}(\mathrm{iii})$ with $\mathrm{BC} 1$, (d) $\mathrm{ABH}$ (i) with $\mathrm{BC}$ 2, (e) $\mathrm{ABH}$ (ii) with $\mathrm{BC} 2$, (f) $\mathrm{ABH}(\mathrm{iii})$ with $\mathrm{BC} 2$.

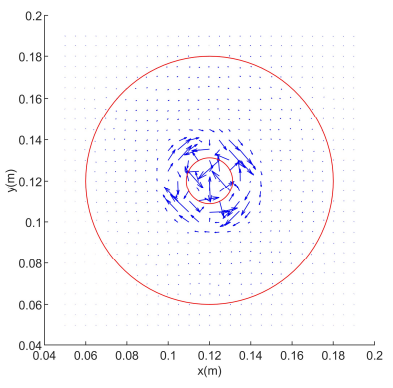

(a)

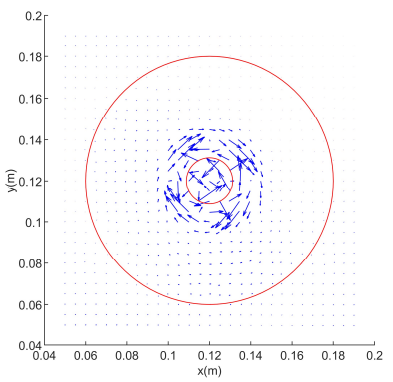

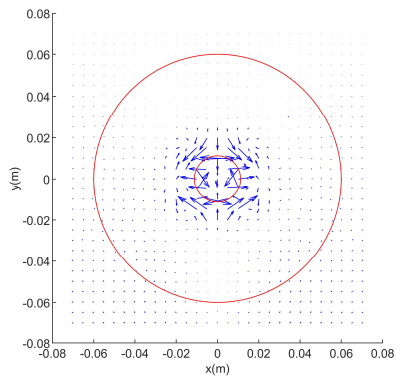

(b)

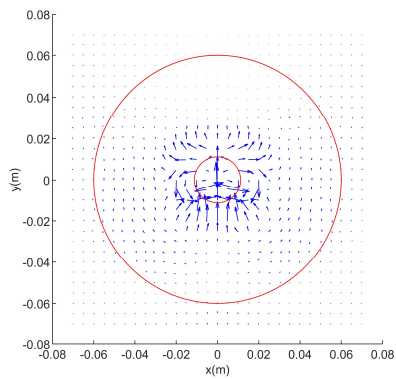

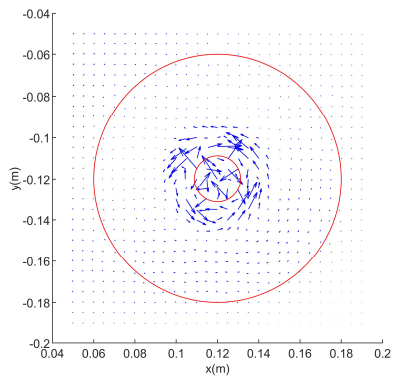

(c)

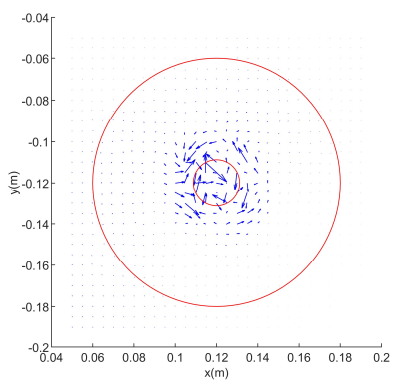


(d) (e) (f)

Figure 7. Power flow transmission graphs at an excitation frequency of $1100 \mathrm{~Hz}$ in $\mathrm{x}-\mathrm{y}$ plane: (a) $\mathrm{ABH}(\mathrm{i})$ with $\mathrm{BC}$ 1, (b) $\mathrm{ABH}(\mathrm{ii})$ with $\mathrm{BC}$ 1, (c) $\mathrm{ABH}(\mathrm{iii})$ with $\mathrm{BC} 1$, (d) $\mathrm{ABH}(\mathrm{i})$ with $\mathrm{BC}$ 2, (e) $\mathrm{ABH}(\mathrm{ii})$ with $\mathrm{BC} 2$, (f) $\mathrm{ABH}($ iii) with $\mathrm{BC} 2$.

Fig. 5-7 show that the vibration power flows to $\mathrm{ABH}$ area obviously when passing through. For the ABH plate with both boundary conditions, power flow density vectors near the central plateau of $\mathrm{ABH}$ are obviously larger than those in other positions, especially in the uniform part of the plate. The power flow transmission graphs with different boundary conditions are similar at the frequency of $1000 \mathrm{~Hz}$ and $1100 \mathrm{~Hz}$. However, at $1050 \mathrm{~Hz}$, the power flow density vectors in locations other than central plateau with BC 2 is much larger than those of $\mathrm{ABH}$ plate with $\mathrm{BC} 1$ which may be due to the natural frequency. The modal analysis results show that for the plate with BC 1, its natural frequencies near $1050 \mathrm{~Hz}$ are $1029.1 \mathrm{~Hz}$ and $1053.3 \mathrm{~Hz}$, however, the natural frequencies of the plate with BC 2 near $1050 \mathrm{~Hz}$ are $1046.4 \mathrm{~Hz}$ and $1053.9 \mathrm{~Hz}$. That is, for the plate with BC 2 , the excitation frequency $1050 \mathrm{~Hz}$ is between two close natural frequencies, which leads to overall vibration of the whole plate. However, even in that case, the $\mathrm{ABH}$ area still gathers a certain amount of energy. That is, the vibration energy is focused on the central area of $\mathrm{ABH}$ structure and the $\mathrm{ABH}$ effect is significant in various excitation frequencies and boundary conditions.

According to the structural intensity $p_{d i}$ calculated at nodes within $\mathrm{ABH}$ areas by Eq. (4), the structural intensity contours of $\mathrm{ABH}(\mathrm{i})$, (ii) and (iii) with different boundary conditions and at different excitation frequencies can be drawn, as shown in Fig. 8-10. Besides, structural intensity contours of $\mathrm{ABH}$ in corresponding positions of the plate with two boundary conditions at $1000 \mathrm{~Hz}, 1050 \mathrm{~Hz}$ and $1100 \mathrm{~Hz}$ are shown in Fig. 11-12.

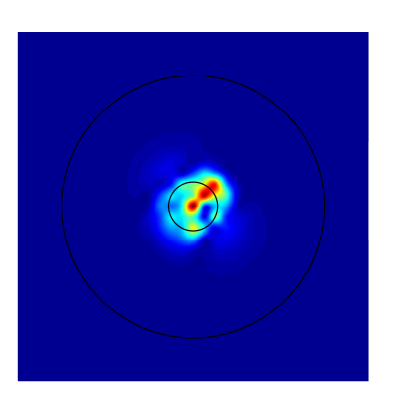

(a)

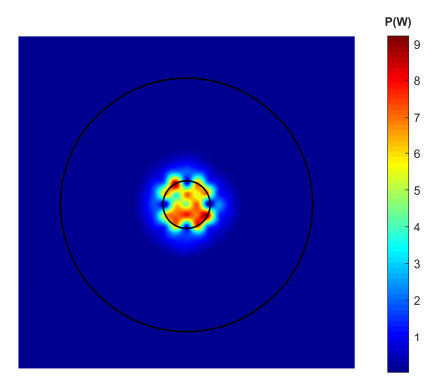

(d)

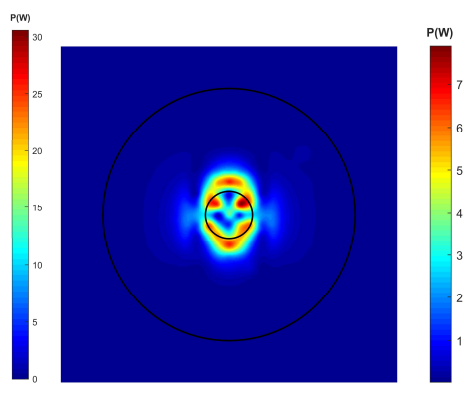

(b)

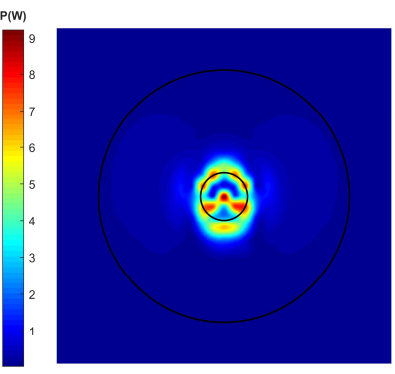

(e)

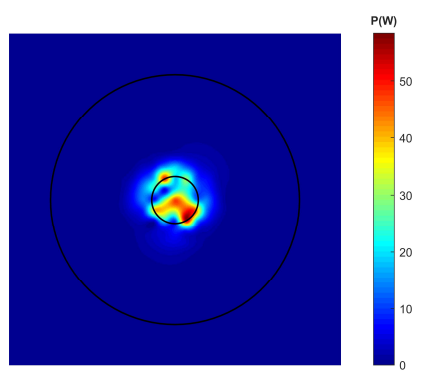

(c)

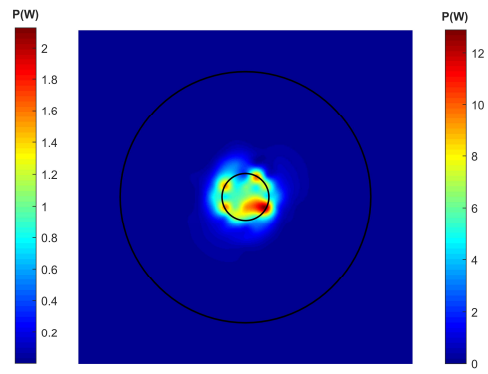

(f)

Figure 8. Structural intensity contours at an excitation frequency of $1000 \mathrm{~Hz}$ : (a) ABH(i) with BC 1, (b) $\mathrm{ABH}$ (ii) with $\mathrm{BC} 1$, (c) $\mathrm{ABH}$ (iii) with $\mathrm{BC} 1$, (d) $\mathrm{ABH}$ (i) with $\mathrm{BC}$ 2, (e) $\mathrm{ABH}$ (ii) with $\mathrm{BC}$, (f) $\mathrm{ABH}$ (iii) with BC 2. 


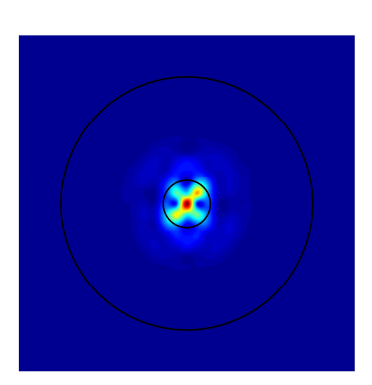

(a)

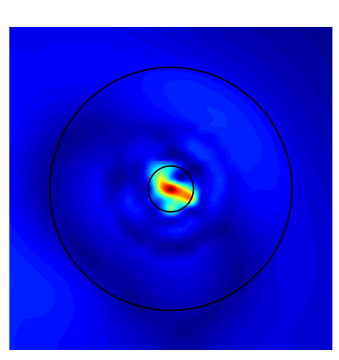

(d)

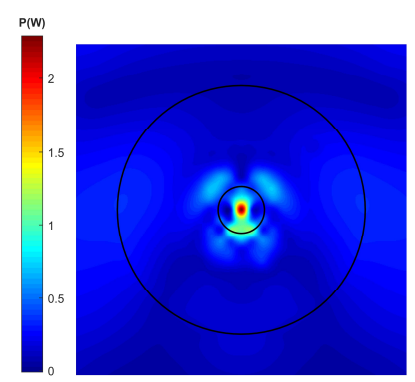

(b)

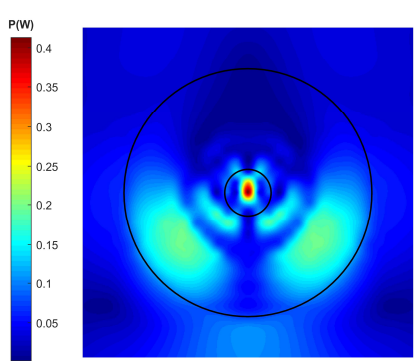

(e)

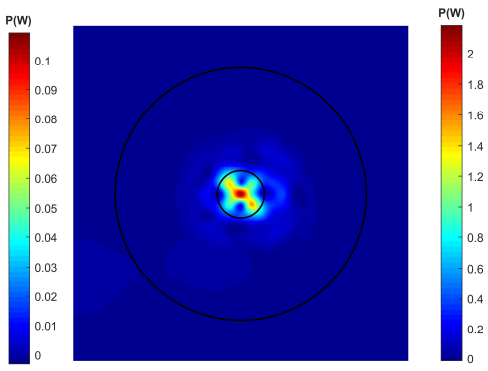

(c)

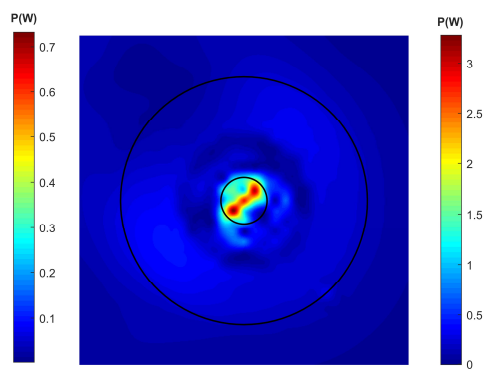

(f)

Figure 9. Structural intensity contours at an excitation frequency of $1050 \mathrm{~Hz}$ : (a) ABH(i) with BC 1, (b) $\mathrm{ABH}($ ii) with $\mathrm{BC} 1$, (c) $\mathrm{ABH}$ (iii) with $\mathrm{BC} 1$, (d) $\mathrm{ABH}(\mathrm{i})$ with $\mathrm{BC}$ 2, (e) $\mathrm{ABH}$ (ii) with $\mathrm{BC}$ 2, (f) $\mathrm{ABH}$ (iii) with BC 2.

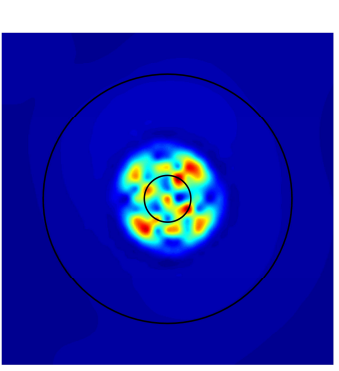

(a)

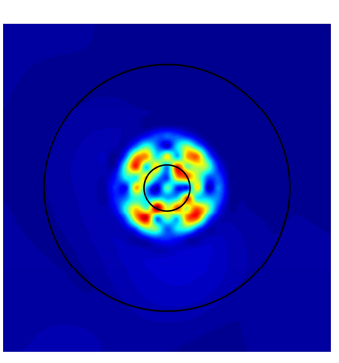

(d)

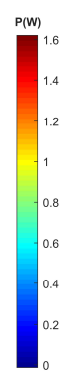

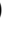

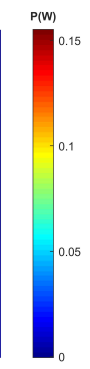

)

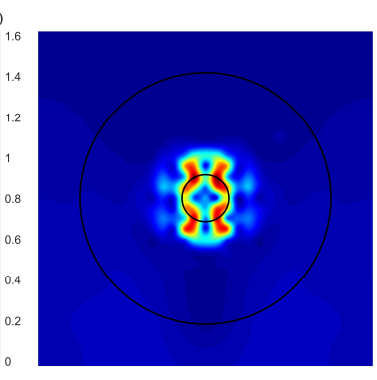

(b)

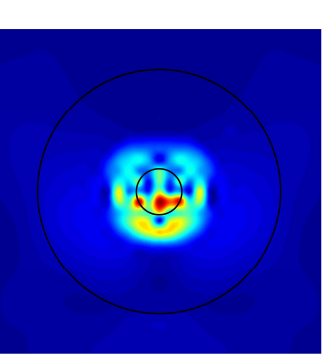

(e)
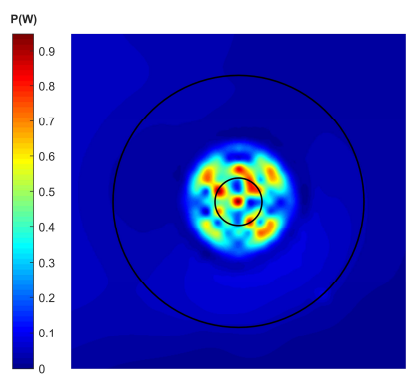

(c)

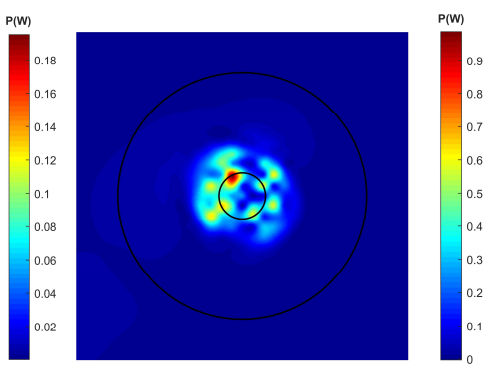

(f)

Figure 10: Structural intensity contours at an excitation frequency of $1100 \mathrm{~Hz}$ : (a) ABH(i) with BC 1, (b) $\mathrm{ABH}($ ii) with $\mathrm{BC} 1$, (c) $\mathrm{ABH}$ (iii) with $\mathrm{BC} 1$, (d) $\mathrm{ABH}$ (i) with $\mathrm{BC}$ 2, (e) $\mathrm{ABH}$ (ii) with $\mathrm{BC}$, (f) $\mathrm{ABH}$ (iii) with $B C 2$. 


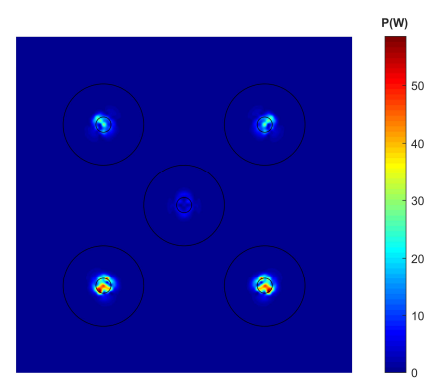

(a)

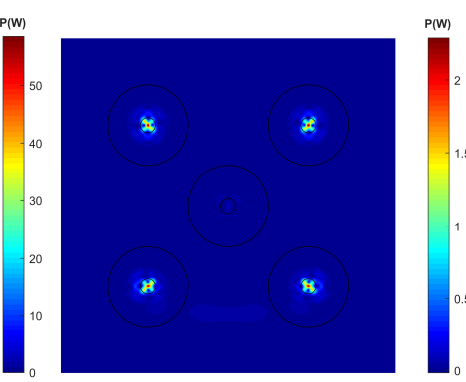

(b)

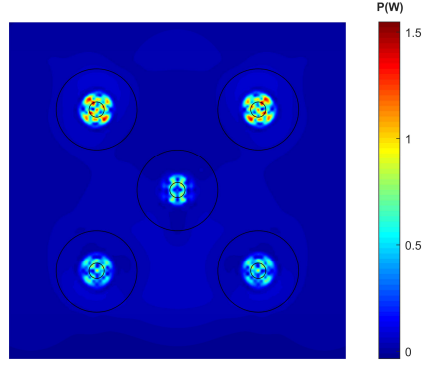

(c)

Figure 11. Structural intensity contours of $\mathrm{ABH}$ in corresponding positions of the plate with $\mathrm{BC} 1$ : (a) $\mathrm{ABH}$ (i) with $\mathrm{BC} 1$, (b) $\mathrm{ABH}$ (ii) with $\mathrm{BC} 1$, (c) $\mathrm{ABH}$ (iii) with $\mathrm{BC} 1$, (d) $\mathrm{ABH}$ (i) with $\mathrm{BC}$ 2, (e) $\mathrm{ABH}$ (ii) with $\mathrm{BC} 2$, (f) $\mathrm{ABH}(\mathrm{iii})$ with $\mathrm{BC} 2$.

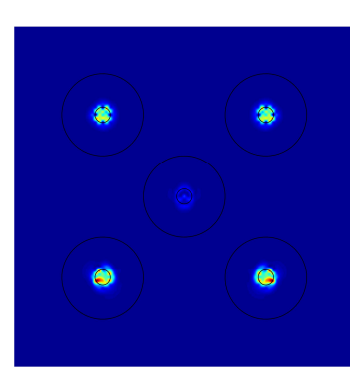

(d)
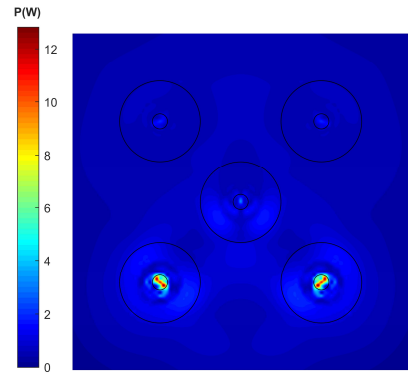

(e)

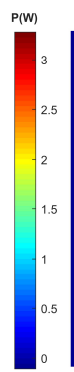

(3)

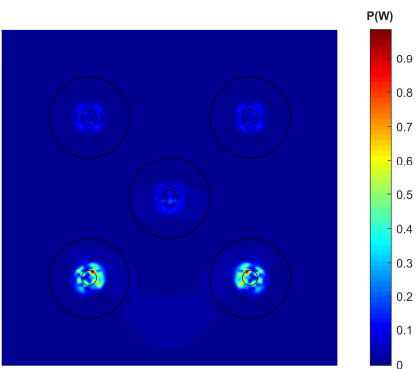

(f)

Figure 12. Structural intensity contours of $A B H s$ in corresponding positions of the plate with $B C 2$ : (a) $\mathrm{ABH}(\mathrm{i})$ with BC 1, (b) $\mathrm{ABH}(\mathrm{ii})$ with $\mathrm{BC}$ 1, (c) $\mathrm{ABH}$ (iii) with $\mathrm{BC}$ 1, (d) $\mathrm{ABH}(\mathrm{i})$ with $\mathrm{BC}$, (e) $\mathrm{ABH}(\mathrm{ii})$ with $\mathrm{BC} 2$, (f) $\mathrm{ABH}(\mathrm{iii})$ with $\mathrm{BC} 2$.

Fig. 8-10 show that high structural intensity areas appear near the central plateau for every $\mathrm{ABH}$ pit, which indicates that vibration energy can indeed be focused near the central areas even if the $\mathrm{ABH}$ pit is imperfect. In this way, the damping materials pasted on such high energy density areas can generate an efficient energy dissipation. Additionally, the area of high energy density is similar in size under both boundary conditions. As shown in Fig. 11 and 12, although energy focalization is realized in every $A B H$ pit, the amount of energy focused is related to the position of $\mathrm{ABH}$. For the plate model under $\mathrm{BC}$ 1 , most of the vibration energy is focalized to the surrounding four ABHs except for the case of $1100 \mathrm{~Hz}$. However, for the plate model under BC 2, most of the vibration energy is focalized to the two ABHs on the lower side except for the case of $1000 \mathrm{~Hz}$.

That is, under certain excitation force, the energy focalization effect of the plate embedded with $\mathrm{ABH}$ array is related to the excitation frequency, the boundary condition and the $\mathrm{ABH}$ position, which should be studied further.

\subsection{Quantitative Analysis of Energy Focalization in the Plate with ABH Array}

Section 2.2 and 2,3 indicate that for $\mathrm{ABH}$ plate, vibration energy can be focused on some specific areas, which is important for performing efficient vibration and noise control by using damping materials. To investigate the energy focalization feature at different position away from the center of $\mathrm{ABH}$, the quantitative analysis is carried out in this section.

Top view of the plate embedded with the two-dimensional $\mathrm{ABH}$ array is schematically shown in Fig. 13. The distance from the plate centre to the reference cross-section is 
$0.21 \mathrm{~m}$. In order to study the relationship between the vibration energy density and $\mathrm{ABH}$ radius, particularly for $\mathrm{ABH}(\mathrm{i})$, (ii) and (iii) in Fig. 13, nodes at 19 different circular sections with radii from $10 \mathrm{~mm}$ to $60 \mathrm{~mm}$ are investigated. Besides, the nodes at the circular section with a radius of $11.22 \mathrm{~mm}$ (radius of the central platform) is also selected and their average vibration power density expressed as Eq. (6) are calculated. Model parameters are set as section 2.1 and 2.2 and the plate is under BC 1.

$$
P_{a d}=\frac{\sum p_{d i}}{N_{s}}
$$

where $P_{a d}$ is the average vibration power density; $p_{d i}$ represents the structural intensity at the ith node as shown in Eq. (4) and $N_{s}$ is the total number of nodes at the selected section.

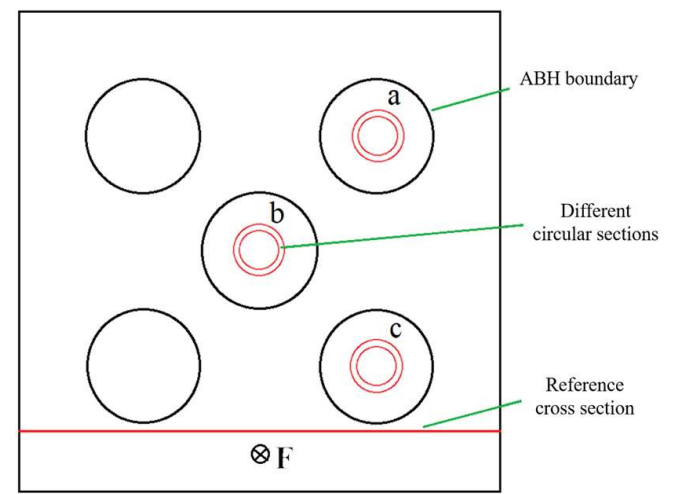

Figure 13. Top view of the plate with embedded two-dimensional $\mathrm{ABH}$ array.

Then, the ratios of average vibration power density at different circular sections of an $\mathrm{ABH}$ to that at the reference cross-section of the plate are calculated. And by using this ratio, the focalization characteristics of the vibration energy at circular sections with different radii in the $\mathrm{ABH}$ can be analyzed. To investigate the vibration energy distribution with $\mathrm{ABH}$ radius under excitation frequency $1000 \mathrm{~Hz}, 1050 \mathrm{~Hz}$ and $1100 \mathrm{~Hz}$, and the influence of natural frequencies, average vibration power density ratios of different circular sections of $\mathrm{ABH}(\mathrm{i}), \mathrm{ABH}(\mathrm{ii})$ and $\mathrm{ABH}(\mathrm{iii})$ at the excitation frequency of $1000 \mathrm{~Hz}, 1002 \mathrm{~Hz}$, $1050 \mathrm{~Hz}, 1072 \mathrm{~Hz}, 1088 \mathrm{~Hz}$, and $1100 \mathrm{~Hz}$ are shown in Fig. $14(1002.0 \mathrm{~Hz}, 1072.1 \mathrm{~Hz}$, and 1088.0 Hz are natural frequencies of the $\mathrm{ABH}$ plate).

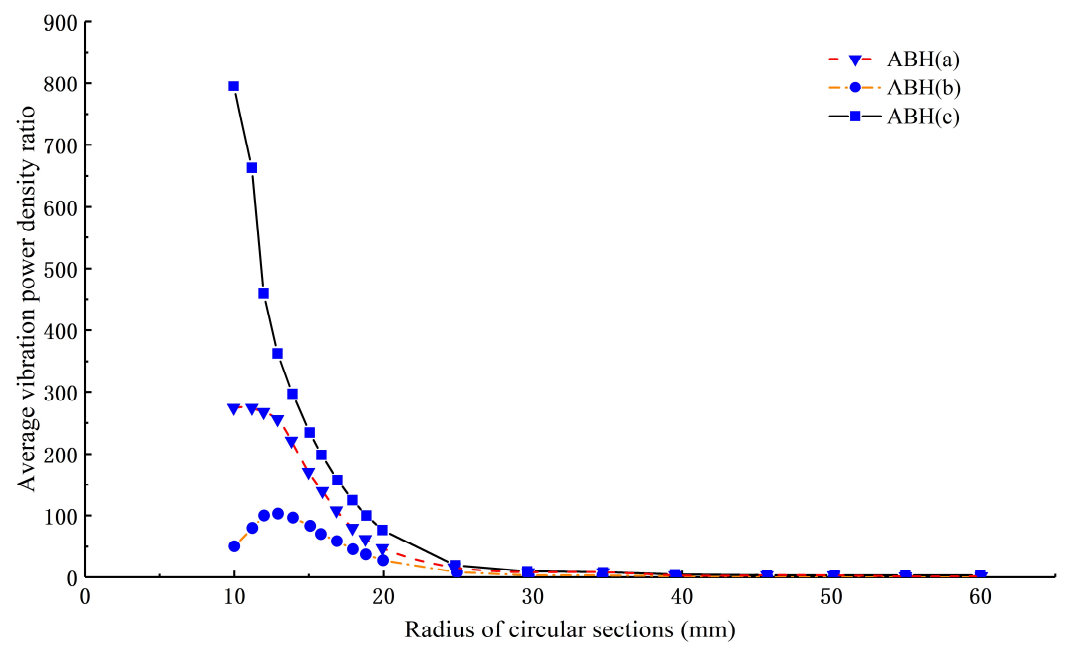


(a)

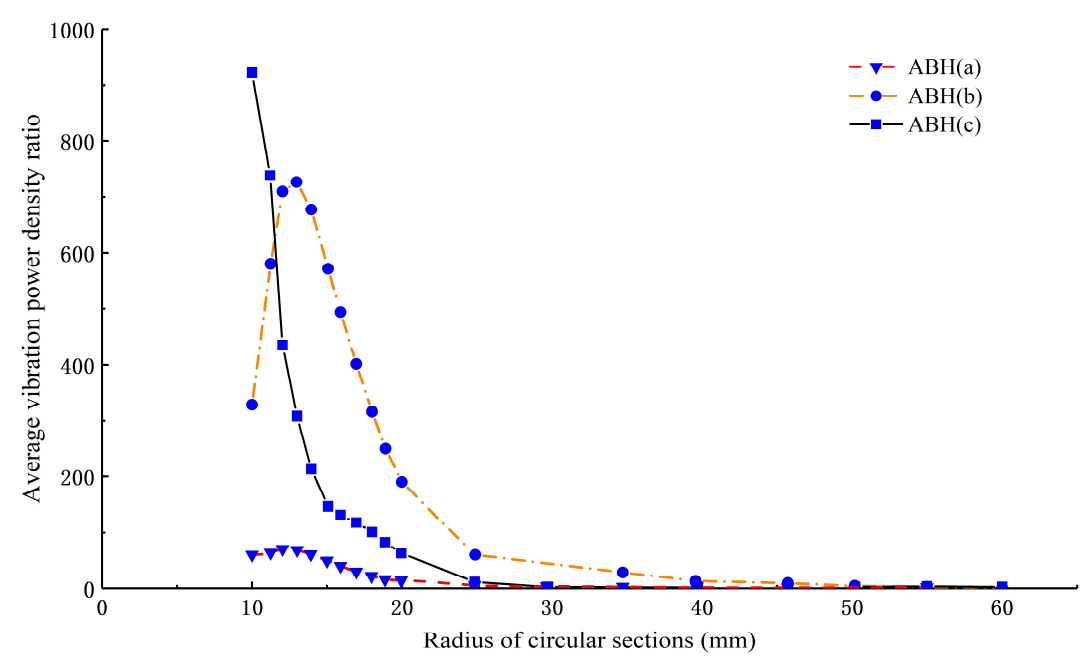

(b)

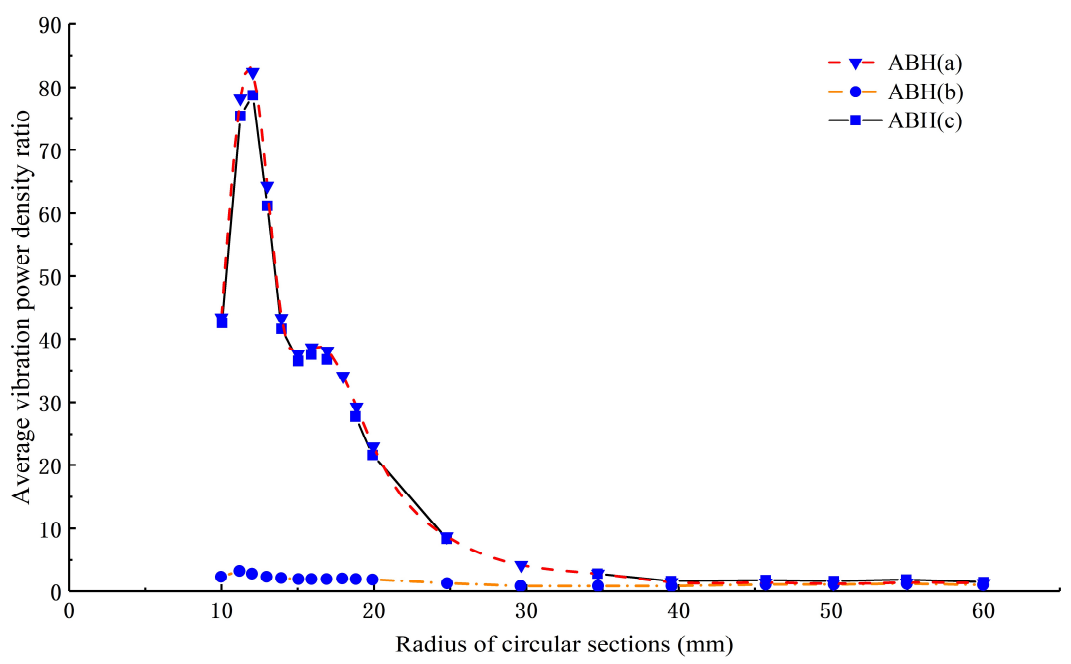

(c)

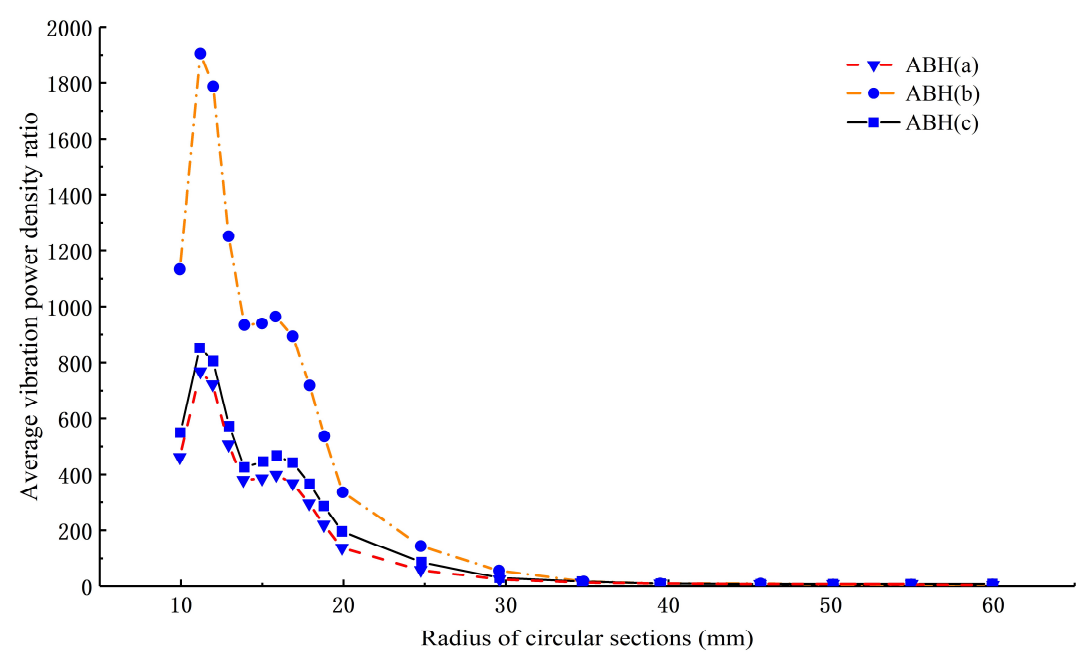


(d)

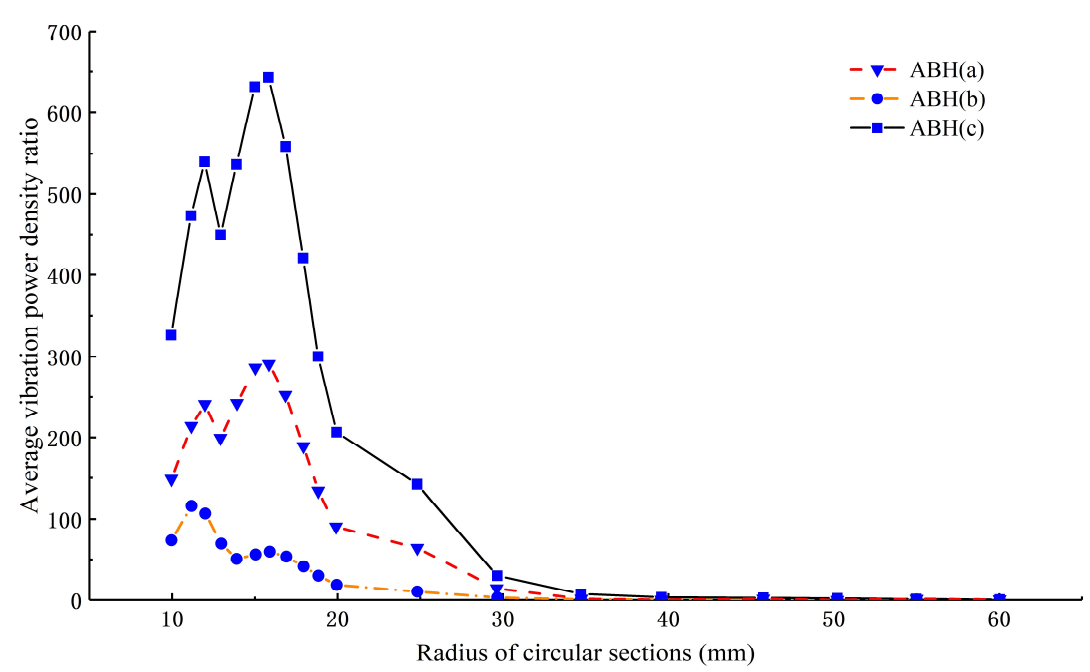

(e)

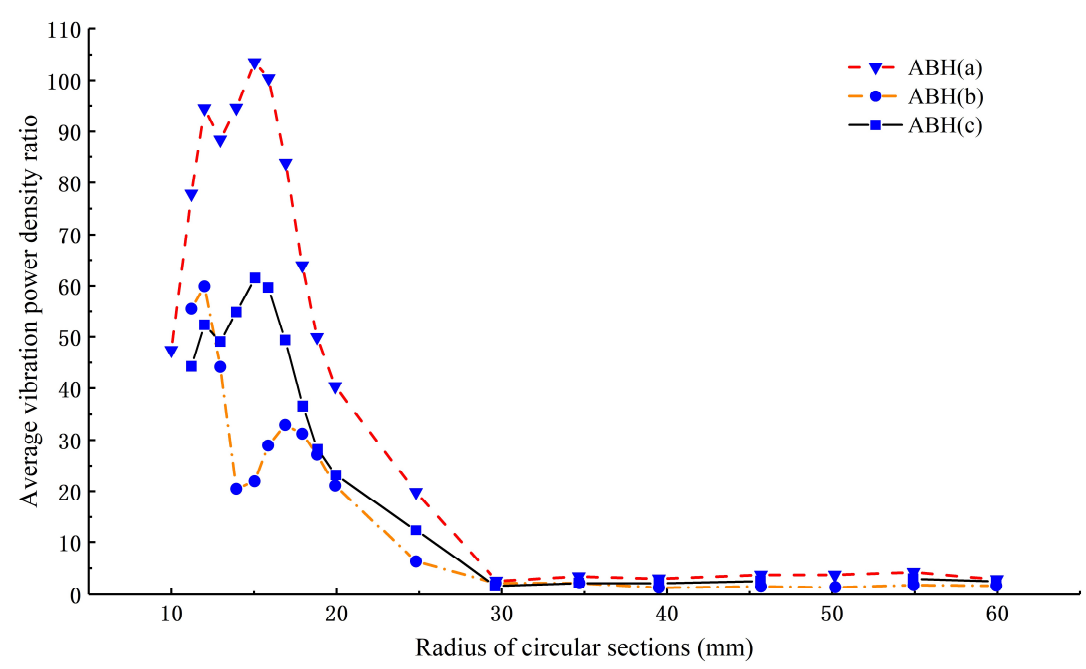

(f)

Figure 14. Average vibration power density ratios of different circular sections of $A B H s$ to reference cross section at different excitation frequencies: (a) $1000 \mathrm{~Hz}$, (b) $1002 \mathrm{~Hz}$, (c)1050 Hz, (d) $1072 \mathrm{~Hz}$, (e) $1088 \mathrm{~Hz}$, (f) $1100 \mathrm{~Hz}$.

As shown in Fig. 14, the average vibration power density ratios at different circular sections in the ABHs are much greater than unity. Particularly, the maximum ratio value can reach hundreds when the excitation frequency is near the natural frequency of the plate, which indicates a significant energy focalization effect.

Additionally, several other observations can be made. First, a peak value in the radius range of $10 \mathrm{~mm}$ to $20 \mathrm{~mm}$ exists for each curve. That indicates the vibration energy focalized in the $\mathrm{ABH}$ centre is not the largest which may be caused by the central plateau. Second, for all excitation frequencies, the energy focalization of $\mathrm{ABH}(\mathrm{i})$ and $\mathrm{ABH}(\mathrm{iii})$ is more effective than that of $\mathrm{ABH}(\mathrm{ii})$. In addition, the ratios are relatively low when the radius of circular section is larger than $30 \mathrm{~mm}$. That is, energy focalization effect is more 
obvious within a $30 \mathrm{~mm}$ radius for every $\mathrm{ABH}$ pit designed in this work, which provides a reference for using damping layers more effectively.

The above observations suggest that the energy focalization effect of a single $\mathrm{ABH}$ cell in the array is related to the excitation frequency, the distance from the $\mathrm{ABH}$ centre and the cell position in the plate. Furthermore, for every $\mathrm{ABH}$ cell at a certain excitation frequency, most of the energy is focalized within a limited area. Therefore, these factors should be concerned in further research to better design the plate embedded with $\mathrm{ABH}$ array.

\section{Effect of Damping Layers in ABH Array on Energy Dissipation and Sound Radia- tion of Plate}

\subsection{FE Model of Plate Embedded with ABH Array with Damping Layers}

In this section, two types of damping layers are introduced to investigate the energy dissipation effect of damping materials coated on $\mathrm{ABH}$ plate. Inspired by the symmetrical one-dimensional ABH wedge [2] shown in Fig. 15(a), the damping layer with a powerlaw varying thickness is introduced as shown in Fig. 15(b) and Fig. 16(b). In addition, damping layers in the same mass but with uniform thickness is also investigated as shown in Fig. 16(c). The results in Section 2.4 indicate that the energy focalization effect is more significant in the area within a radius of $30 \mathrm{~mm}$. Therefore, the profile of damping layers is designed to be symmetrical with that of the $\mathrm{ABH}$ and with radius of $30 \mathrm{~mm}$. The parameters of the damping layers are shown in Table 3. FE model of the plate structure with two-dimensional ABH array and damping layers is illustrated in Fig. 16(a). The weight of the plate with $\mathrm{ABH}$ array and damping layers is $6.88 \mathrm{~kg}$ while that of the uniform plate with only damping layers is $7.81 \mathrm{~kg}$. That is, the acoustic black holes result in about $11.9 \%$ weight saving.

Table 3. Parameters of the damping layer.

\begin{tabular}{ccccc}
\hline Parameter & $\rho_{p}\left[\mathrm{~kg} / \mathrm{m}^{3}\right]$ & $E_{\mathrm{p}}[\mathrm{GPa}]$ & $v$ & Loss factor \\
\hline Value & 950 & 5.0 & 0.3 & 0.3 \\
\hline
\end{tabular}

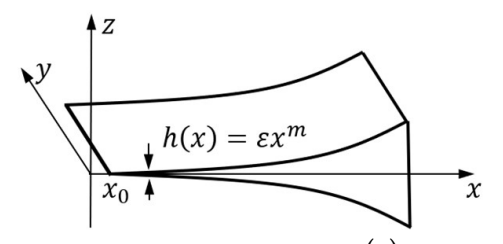

(a)

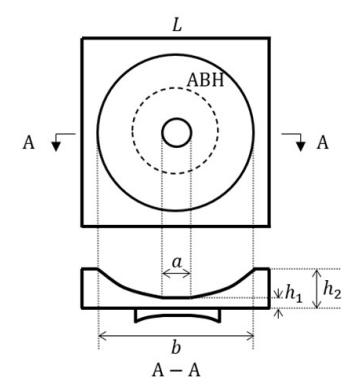

A-

Figure 15. (a) A symmetrical one-dimensional ABH structure, (b) A two-dimensional ABH indentation with varying thickness damping layers.

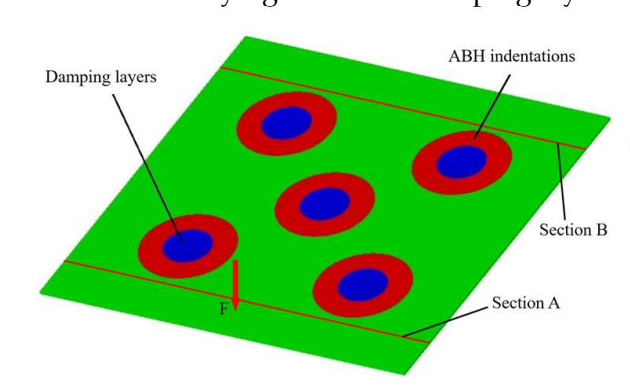

(a)

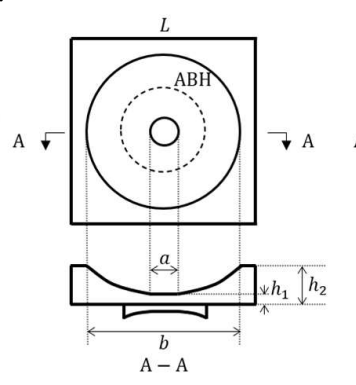

(b)

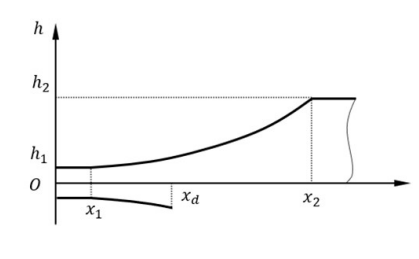

(b)

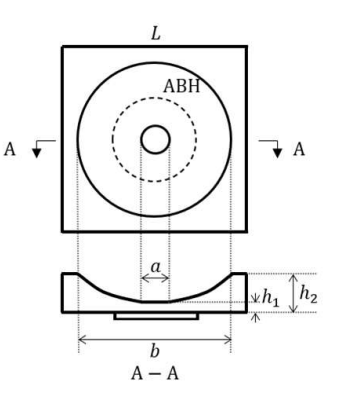

(c) 
Figure 16. A schematic diagram of FE model: (a) FE model of plate structure with ABHs and damping layers, (b) A two-dimensional $\mathrm{ABH}$ indentation with varying thickness damping layers, (c) A two-dimensional $\mathrm{ABH}$ indentation with uniform thickness damping layers.

\subsection{Energy Dissipation in Plate Embedded with ABH Array with Damping Layers}

Fig. 16 (a) shows the top view of the plate embedded with the two-dimensional ABH array with damping layers. Sections A and B are cross-sections of the plate. Vibration energy can be expressed as average power flow at the given section per unit time as defined in Eq. (5). Consequently, to evaluate the energy dissipation characteristics of the plate embedded with $\mathrm{ABH}$ array with different damping layers, the difference of average power flow between section $\mathrm{A}$ (before $\mathrm{ABHs}$ ) and section $\mathrm{B}$ (after $\mathrm{ABHs}$ ) is calculated.

For the plate embedded with $\mathrm{ABH}$ array with varying thickness damping layers, uniform thickness damping layers and without damping layers under both BC 1 and BC 2, the difference of vibration energy per time unit (average power flow) between section $\mathrm{A}$ and $\mathrm{B}$ is calculated in frequency domain respectively. Additionally, the vibration energy difference of a uniform plate with the same varying thickness damping layers with BC 1 is also calculated as a reference. Results are shown in Fig. 17 and 18.

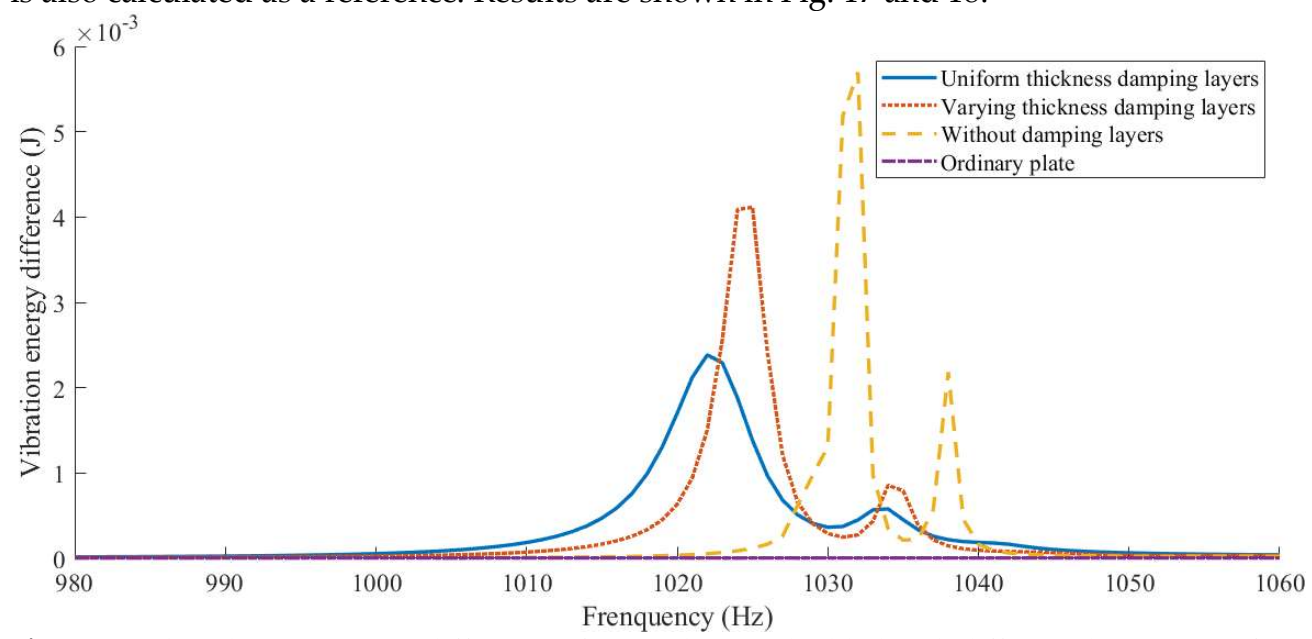

Figure 17. The vibration energy difference of $\mathrm{ABH}$ plates embedded with different damping configurations and a reference plate with BC 1 .

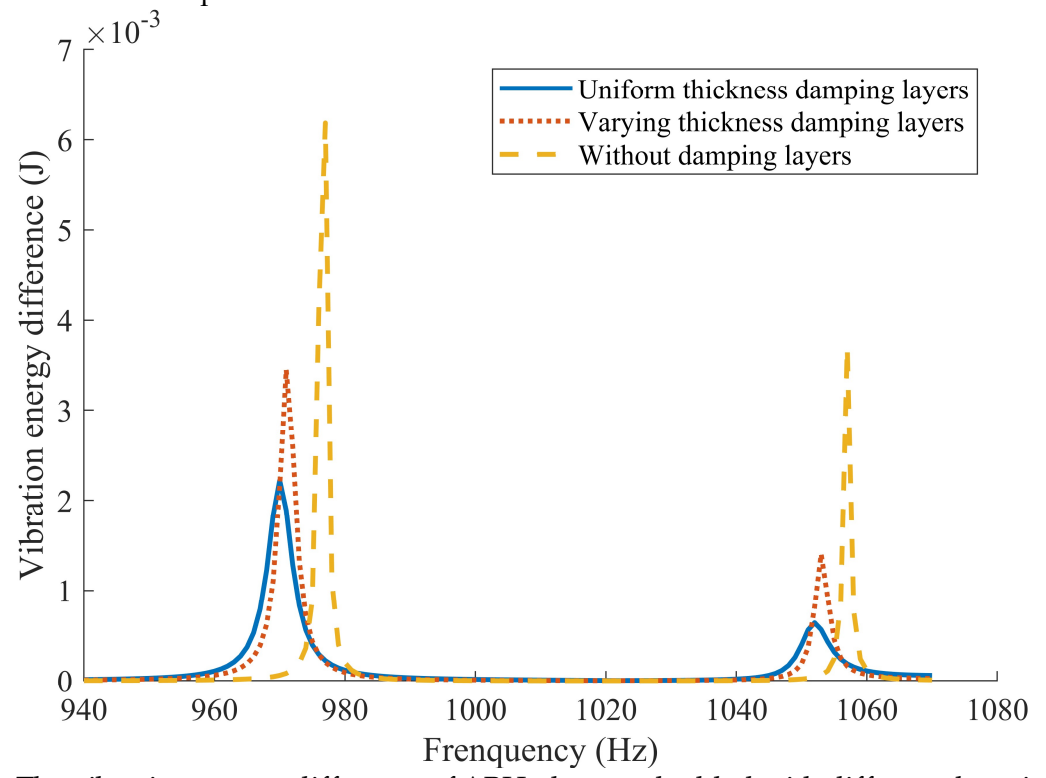

Figure 18. The vibration energy difference of $\mathrm{ABH}$ plates embedded with different damping configurations with BC 2 . 
Fig. 17 shows that every curve has two peaks, and the vibration energy difference between section $\mathrm{A}$ and $\mathrm{B}$ of the plates embedded with $\mathrm{ABH}$ array with different damping layers are obviously higher than that of the uniform plate with damping layers in the range of 980-1060 Hz. This indicates that the energy dissipation efficiency of damping materials is obviously improved because of the ABHs, particularly in the range of 1020$1040 \mathrm{~Hz}$. Besides, for plates embedded with ABH array the peaks occur at different frequencies for different damping configurations. This indicates that the damping materials may change the energy distribution of plate embedded with $\mathrm{ABH}$ array in the frequency domain to some extent and reduce the frequency at which the $\mathrm{ABH}$ array starts to generate the effect. Moreover, due to the energy dissipation of damping layers, the peak energy difference values of $\mathrm{ABH}$ plate with uniform damping layers and $\mathrm{ABH}$ plate with varying thickness damping layers are smaller than that of $\mathrm{ABH}$ plate without damping layers. The peak value of $\mathrm{ABH}$ plate with uniform damping layers is smaller than that of $\mathrm{ABH}$ plate with varying thickness damping layers, which indicates that the uniform damping layers have a better energy dissipation effect than varying thickness damping layers in this case.

Several conclusions can be drawn from Fig. 18. First, similar to the ABH plate with $\mathrm{BC} 1$, every curve has two peaks and the peak values range from larger to small is $\mathrm{ABH}$ plate without damping layers, $\mathrm{ABH}$ plate with varying thickness damping layers and $\mathrm{ABH}$ plate with uniform damping layers, respectively. Besides, the curves also show that damping layers change the energy distribution in the frequency domain and reduce the frequency where the $\mathrm{ABH}$ starts to work. Moreover, as the boundary condition is changed, the frequency corresponding to the first peak is lower than that with BC 1 and the frequency corresponding to the second peak value is higher than that with BC 1, which means that boundary condition can also influence the energy distribution in the frequency domain.

Therefore, the energy focalization characteristics of $\mathrm{ABH}$ structure can be used to achieve effective energy dissipation by using relatively small damping layers and the dissipation effect of uniform damping layers is better than power-law profile thickness damping layers in this case. Besides, damping layers attached to $\mathrm{ABH}$ areas and boundary condition of the plate can change the energy distribution in the frequency domain. At the same time, the mass of plate with $\mathrm{ABH}$ array is less than that of the uniform plate, so the contradiction between the plate lightweight and vibration control can be harmonized to some extent.

\subsection{Sound Radiation of Plate Embedded with ABH Array with Damping Layers}

To investigate the sound radiation of the plate embedded with $\mathrm{ABH}$ array with the damping layers, a coupled acoustic-plate system is introduced as shown in Fig. 19, and the averaged sound pressure level of the top surface of the air field is calculated. At the same time, a reference acoustic-plate model embedded with $\mathrm{ABH}$ array but without damping layers is also established and its sound pressure level is also calculated. In this way, the noise attenuation effect can be analyzed. The results are shown in Fig. 20 ( $p_{\text {ref }}=2 \times 10^{-5} \mathrm{~Pa}$, plate model under BC 1, with uniform thickness damping layers). 


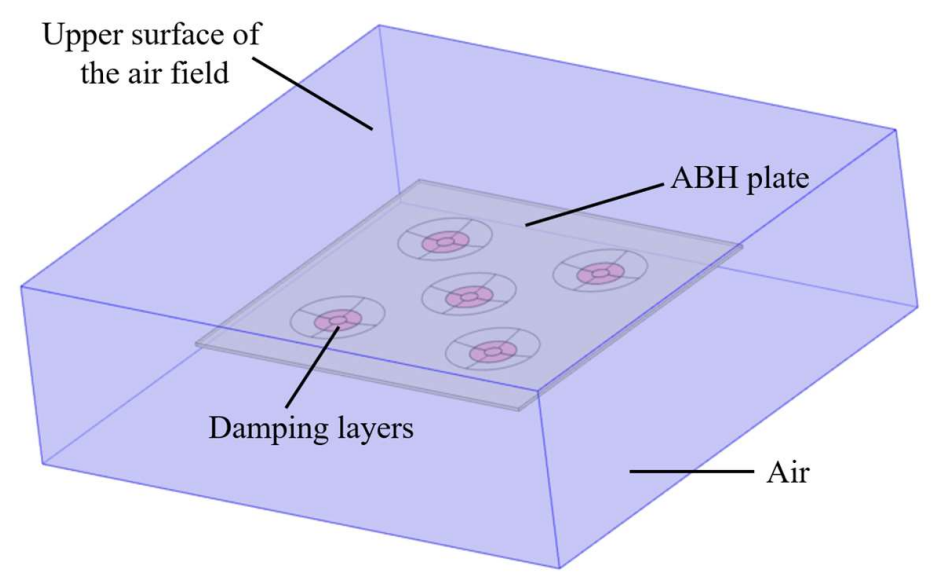

Figure 19. The acoustic-ABH plate coupling model.

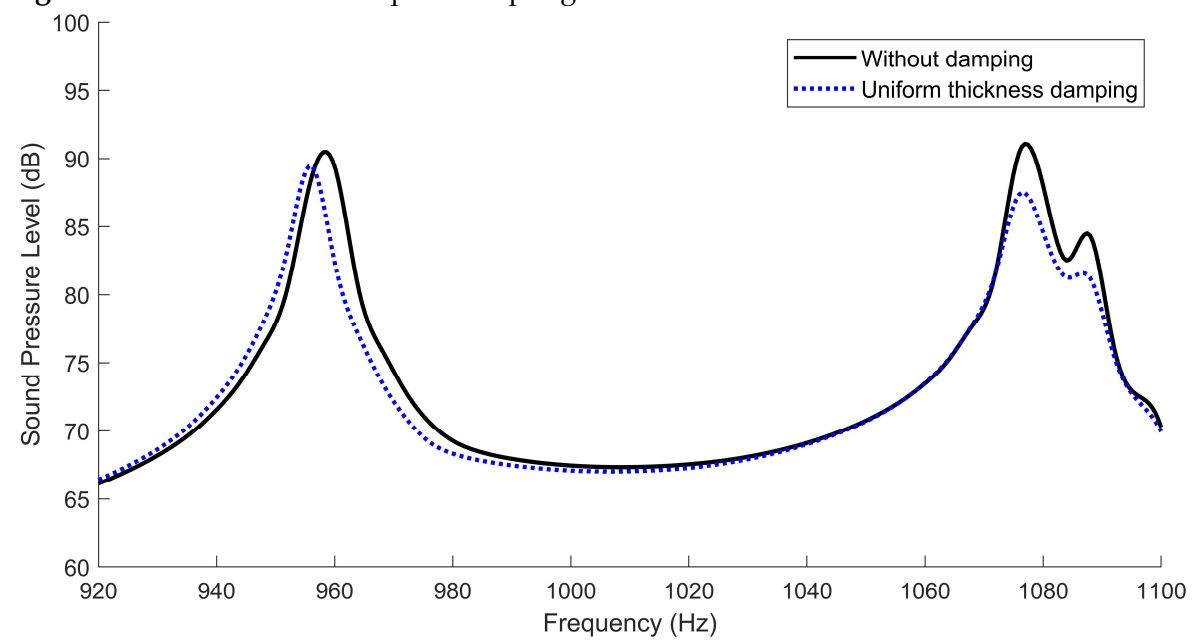

Figure 20. Sound pressure level of plates embedded with $\mathrm{ABH}$ array with/without damping layers.

Fig. 20 shows that for the first peak value in this frequency band, the sound pressure level of the plate with damping layers at about $956 \mathrm{~Hz}$ is below that of the plate without damping layers for approximately $1 \mathrm{~dB}$. In addition, the second and third peak values at about $1075-1088 \mathrm{~Hz}$ are below these of the plate without damping layers for about 3-4 $\mathrm{dB}$, which shows a significant noise reduction effect in the range of 920-1100 Hz. At the same time, Fig. 17 shows that the plate embedded with $\mathrm{ABH}$ array has a significant vibration energy dissipation effect in the frequency range of 1020 to $1040 \mathrm{~Hz}$. That is, the plate embedded with $\mathrm{ABH}$ array with damping layers designed in this paper can obviously reduce both vibration and noise in that frequency band.

\section{Conclusions}

In this paper, a plate model embedded with the array of five two-dimensional ABHs are established. And the energy propagation characteristics arising from $\mathrm{ABH}$ is analyzed by using FEM and power flow method. Additionally, the energy focalization effect is studied quantitatively by calculating average vibration power density at different plate sections. Further, the effects of damping materials and different boundary conditions on model energy dissipation are also investigated. Finally, the effects of damping layers on radiated sound power are studied. Conclusions are reached as follows:

(1) In the low frequency range of $50-180 \mathrm{~Hz}$, plate embedded with $\mathrm{ABH}$ array has a better energy gathering performance than the plates embedded with a large $\mathrm{ABH}$ or a single $\mathrm{ABH}$, which may be due to the influence of low-order modes. This property is conducive to the application of $\mathrm{ABH}$ array in compact structures such as vehicle body panels. 
(2) For the plate embedded with five $\mathrm{ABH}$ indentations designed in this paper, the power flow density at the $\mathrm{ABH}$ central area is much higher than that of other areas. That is, the $\mathrm{ABH}$ effect is very obvious. However, under certain excitation force, the energy focalization effect of the plate embedded with $\mathrm{ABH}$ array is related to the positions of $\mathrm{ABH}$ pits.

(3) The average vibration power density ratios at different circular sections in $\mathrm{ABH}$ are greater than 1 . And the maximum value can reach hundreds when excitation frequency is near the natural frequency of plate, which indicates a significant energy focalization effect of the plate embedded with $\mathrm{ABH}$ array. In addition, the energy focalization effect is not obvious when the radius of the circular section is larger than $0.03 \mathrm{~m}$, which provides a reference for using damping layers more effectively.

(4) Results in Section 3.2 shows that for the plate designed in this paper, damping materials can change the plate energy distribution in the frequency domain to some extent and reduce the frequency where the ABH array starts to work. Moreover, due to the energy dissipation of damping layers, the peak energy difference values of $\mathrm{ABH}$ plate with damping layers is smaller than that of the $\mathrm{ABH}$ plate without damping layers. Results also show that the uniform damping layers have a better energy dissipation effect than varying thickness damping layers in this case.

(5) The energy focalization characteristics of plates embedded with ABH indentations can be used to achieve effective energy dissipation with relatively small damping layers. At the same time, the mass of plate with $\mathrm{ABH}$ indentations is less than that of the uniform plate, so the contradiction between the plate lightweight and vibration control can be harmonized to some extent.

(6) The radiated sound power level of the plate embedded with $\mathrm{ABH}$ indentations with damping layers is reduced by $1-4 \mathrm{~dB}$ compared with the $\mathrm{ABH}$ plate without damping layers, which shows that the using of damping layer in $\mathrm{ABH}$ areas can obviously reduce radiated sound.

In this paper, only the characteristics of the plate embedded with $\mathrm{ABH}$ array in a certain excitation frequency band are investigated. However, in fact, the analysis method in this paper can be used in any excitation frequency band. In addition, experimental test to verify the vibration and noise control performance of the plate embedded with $\mathrm{ABH}$ array is ongoing. Future work will explore the optimization of the $\mathrm{ABH}$ array for optimal noise \& vibration control and weight minimization, including the $\mathrm{ABH}$ position, size, and $\mathrm{ABH}$ cell parameters.

Supplementary Materials: The following are available online at www.mdpi.com/xxx/s1, Figure S1: title, Table S1: title, Video S1: title.

Author Contributions: Conceptualization, Liu Xiandong, Shan Yingchun and He Tian.; methodology, Liu Xiandong.; software, Liang Haoming.; validation, Liang Haoming, Bao Yue and Yuan Jiakai; formal analysis, Liang Haoming.; investigation, Liang Haoming; resources, Bao Yue.; data curation, Liang Haoming; writing-original draft preparation, Liang Haoming; writing-review and editing, Liu Xiandong; visualization, Liang Haoming; supervision, Liu Xiandong; project administration, Liang Haoming; funding acquisition, Liu Xiandong All authors have read and agreed to the published version of the manuscript." Please turn to the CRediT taxonomy for the term explanation. Authorship must be limited to those who have contributed substantially to the work reported.

Funding: This research was funded by Natural Science Foundation of China., grant number 11972003.

Acknowledgments: The authors would like to thank the financial support provided by the Natural Science Foundation of China (Grant No. 11972003).

Conflicts of Interest: The authors declare no conflict of interest. The funders had no role in the design of the study; in the collection, analyses, or interpretation of data; in the writing of the manuscript, or in the decision to publish the results. 


\section{References}

In the text, reference numbers should be placed in square brackets [ ] and placed before the punctuation; for example [1], [1-3] or $[1,3]$. For embedded citations in the text with pagination, use both parentheses and brackets to indicate the reference number and page numbers; for example [5] (p. 10), or [6] (pp. 101-105).

1. Mironov M A. Propagation of a flexural wave in a plate whose thick-ness decreases smoothly to zero in a finite interval. Soviet Physics-Acoustics, 1988, 34(3): 318-319.

2. Krylov V V. New type of vibration dampers utilizing the effect of acoustic 'black holes'. Acta Acustica united with Acustica, 2004, 90(5): 830-837.

3. Krylov V V, Tilman F J B S. Acoustic 'black holes' for flexural waves as effective vibration dampers. Journal of Sound and Vibration, 2004, 274(3-5): 605-619.

4. Krylov V V, Winward R. Experimental investigation of the acoustic black hole effect for flexural waves in tapered plates. Journal of Sound and Vibration, 2007, 300(1-2): 43-49.

5. Conlon S C, Fahnline J B, Semperlotti F. Numerical analysis of the vibroacoustic properties of plates with embedded grids of acoustic black holes. Journal of Acoustical Society of America, 2015, 137(1): 447-457.

6. Li X, Ding Q. Sound radiation of a beam with a wedge-shaped edge embedding acoustic black hole feature. Journal of Sound and Vibration, 2019, 439(20): 287-299.

7. Yan S, Lomonosov A M, Shen Z. Numerical and experimental study of Lamb wave propagation in a two-dimensional acoustic black hole. Journal of Applied Physics, 2016, 119(21): 214902.

8. Krylov V V. Propagation of plate bending waves in the vicinity of one- and two-dimensional acoustic black hole. Proceedings of the First International ECCOMAS Thematic Conference on Computational Methods in Structural Dynamics and Earthquake Engineering, Rethymno, Greece, 2007.

9. O'Boy D J, Krylov V V. Damping of flexural vibrations in circular plates with tapered central holes. Journal of Sound and Vibration, 2011, 330(10): 2220-2236.

10. O'Boy D J, Krylov V V, Kralovic V. Damping of flexural vibrations in rectangular plates using the acoustic black hole effect. Journal of Sound and Vibration, 2010, 329(22): 4672-4688.

11. Huang W, Ji H L, Qiu J H, et al. Analysis of ray trajectories of flexural waves propagating over generalized acoustic black hole indentations. Journal of Sound and Vibration, 2018, 417(17): 216-226.

12. Conlon S C, Fahnline J B, Shepherd M R, et al. Vibration control using grids of Acoustic Black Holes: How many is enough. In: Inter-Noise, San Francisco, USA, 2015.

13. Conlon S C, Fahnline J B, Semperlotti F, et al. Enhancing the low frequency vibration reduction performance of plates with embedded acoustic black holes. In :Inter-Noise, Melbourne, Australia, 2014.

14. Huang W, Ji H L, Qiu J H, et al. Wave energy focalization in a plate with imperfect two-dimensional acoustic black hole indentation. ASME Journal of Vibration and Acoustics, 2016, 138(6): 061004-1-12.

15. Weisser T, Foltête E, Bouhaddi N, et al. A power flow mode approach dedicated to structural interface dynamic characterization. Journal of Sound and Vibration, 2015, 334(6): 202-218.

16. $\mathrm{Wu} \mathrm{W}, \mathrm{Yin} \mathrm{X}, \mathrm{Li} \mathrm{H}$, et al. Power flow analysis of built-up plate structures using the dynamic stiffness method. Journal of Vibration and Control, 2018, 24(13): 2815-2831.

17. Stephen A H, Richard P S. Predictions of structural intensity fields using solid finite elements. Noise Control Engineering, 1999, 47(6): 209-217.

18. Prill O, Roos C, Bush R. Finite element simulations of acoustic black holes as lightweight damping treatments for automotive body panels with application to full vehicle interior wind noise predictions. In: Inter-Noise, Hamburg, Germany, 2016.

19. Wang X R, Liu X D, Tai J F, et al. A novel method of reducing the acoustic emission wave reflected by boundary based on acoustic black hole. Ultrasonics, 2019, 94: 292-304.

20. Pelat A, Gautier F, Conlon S C, et al. The acoustic black hole: A review of theory and applications. Journal of Sound and Vibration, 2020, 476(23): 115316.

21. Krylov V V. Overview of localised flexural waves in wedges of power-law profile and comments on their relationship with the acoustic black hole effect. Journal of Sound and Vibration, 2020, 468(3): 115100. 